Corresponding author: rsalgia@coh.org

(c) 2020 Roth et al. This article is distributed under the terms of the Creative Commons Attribution-NonCommercial License, which permits reuse and redistribution, except for commercial purposes, provided that the original author and source are credited.

Ontology term: lung adenocarcinoma

Published by Cold Spring Harbor Laboratory Press

doi:10.1101/mcs.a005785

\section{Prolonged survival and response to tepotinib in a non-small-cell lung cancer patient with brain metastases harboring MET exon 14 mutation: a research report}

\author{
Katherine G. Roth, ${ }^{1}$ Isa Mambetsariev, ${ }^{1}$ and Ravi Salgia \\ Department of Medical Oncology and Therapeutics Research, City of Hope, Duarte, California 91010, USA
}

Abstract Tyrosine kinase inhibitors (TKIs) have transformed the standard of care in lung cancer. A number of TKls have been discovered that specifically target oncogenes, including MET receptor tyrosine kinase. Second-generation MET TKIs are showing improved efficacy over first-generation TKIs. Herein, we report a case of a patient with metastatic lung adenocarcinoma harboring a MET exon 14 splice site mutation who has had prolonged disease control by a second-generation MET-TKI tepotinib. A 66-yr-old man was diagnosed with stage IV lung adenocarcinoma. He was started on carboplatin, paclitaxel, and bevacizumab, but had severe toxicity. He was switched to pembrolizumab as his tumor was PD-L1 70\%, and molecular testing was not yet performed because of insufficient tissue. A bronchoscopy with endobronchial ultrasound was performed and a MET exon 14 splice site mutation was detected by next-generation sequencing. Upon progression, he was then enrolled in a clinical trial of tepotinib and continues with stable disease for more than 45 cycles and 31 mo. The MET receptor tyrosine kinase and the ligand hepatocyte growth factor (HGF) have been implicated as oncogenes and drivers of non-small-cell lung cancer (NSCLC). Newer MET TKIs including capmatinib and tepotinib more recently showed not only improved localized control and response, but early data suggests intracranial activity as compared to first-generation MET TKIs, both in the front-line and the refractory setting. This is a case report demonstrating an effective duration of response in a patient with widely metastatic lung adenocarcinoma harboring a MET exon 14 mutation.

[Supplemental material is available for this article.]

\section{INTRODUCTION}

MET tyrosine kinase inhibitors (TKIs) and anti-MET antibody-drug conjugates have shown favorable antitumor efficacy in patients with non-small-cell lung cancer (NSCLC) (Kim and Kim 2017; Ma et al. 2019). MET-selective TKIs, such as capmatinib and tepotinib, are showing promise in clinical trials because of their on-target activity for tumors with MET exon 14 skipping (Wolf et al. 2018). We present a case of a 66-yr-old man with metastatic NSCLC with PD-L1 70\% and harboring a MET exon 14 mutation who has had a prolonged, sustained response on tepotinib therapy.

\footnotetext{
${ }^{1}$ These authors contributed equally to this work and should be considered co-first authors.
} 


\section{RESULTS}

\section{Clinical Presentation}

A 66-yr-old Asian man, never smoker, first presented with dyspnea on exertion, and cardiac magnetic resonance imaging revealed biventricular masses consistent with metastatic disease. Computed tomography detected a right upper lobe mass $(4.7 \times 5.7 \times 5.2 \mathrm{~cm}$; Fig. 1A), subcentimeter pulmonary nodules, anterior mediastinal and hilar lymphadenopathy, multiple biventricular endocardial masses, multiple hepatic masses, bilateral adrenal nodules, and lytic lesions. Magnetic resonance imaging of the brain showed multiple subcentimeter brain lesions (Fig. 1D). A fine-needle aspiration biopsy of the liver confirmed primary stage IV lung adenocarcinoma (T3N3M1c) with PD-L1 70\%, but was insufficient for molecular testing. The patient received carboplatin (AUC 6) and paclitaxel $\left(200 \mathrm{mg} / \mathrm{m}^{2}\right)$ chemotherapy for two cycles, with the addition of bevacizumab $(15 \mathrm{mg} / \mathrm{kg})$ to the second cycle. However, his treatment course was complicated by grade 3 fatigue and grade 3 neuropathy. Given these toxicities and the lack of known actionable alterations at the time, the patient was then initiated on pembrolizumab. Additionally, at this time a bronchoscopy with endobronchial ultrasound was performed and samples were sent for next-generation sequencing (OncoPlus), which revealed a MET exon 14 splice site mutation and was equivocal for amplification. Pembrolizumab was halted after 9 mo because of adrenal insufficiency and disease progression of the patient's right upper lobe mass and lymphadenopathy (Fig. 1B). However, brain imaging demonstrated small foci that could represent treated metastases and no new metastases (Fig. 1E). The patient was then enrolled in a clinical trial (NCT02864992) and
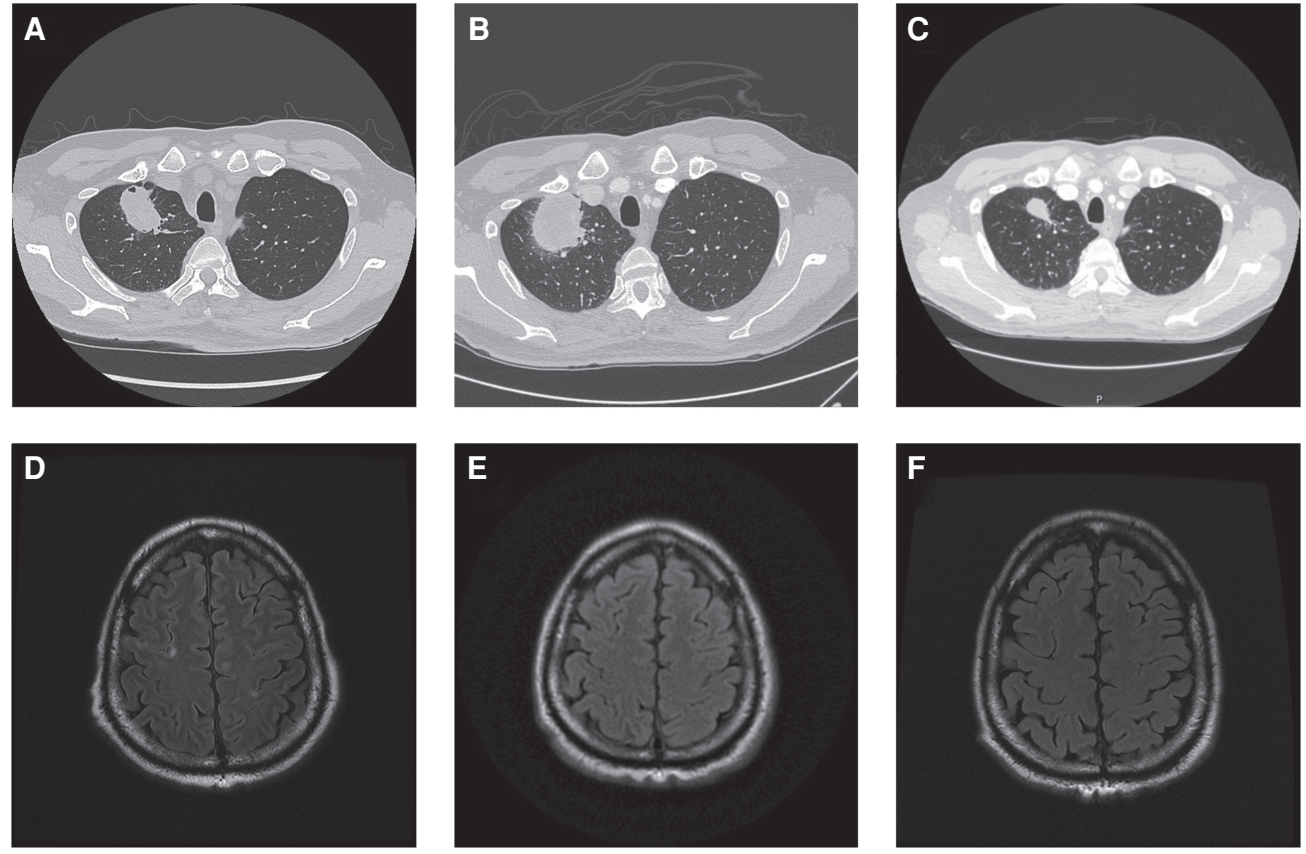

Figure 1. Computed tomography (CT) and magnetic resonance imaging (MRI) scans at diagnosis, after therapy, and at latest follow-up. Primary right upper lung mass at diagnosis $(A)$, after 13 cycles of pembrolizumab $(B)$, and current imaging after 40 cycles of tepotinib therapy $(C)$ illustrating a response to tepotinib therapy. Several nodule areas of FLAIR intensity consistent with brain metastases at diagnosis (D), after 13 cycles of pembrolizumab (E), and current imaging after 40 cycles of tepotinib therapy $(F)$. Of note, the patient had additional foci of hyperintensity in his brain imaging, including a $7 \times 8-\mathrm{mm}$ right middle frontal gyrus lesion, that also resolved with treatment and have not recurred. 
initiated on tepotinib (500 mg tablet daily). This patient who initially presented with diffuse metastatic disease now continues with overall stable disease for more than 45 cycles and 31 mo after initiating tepotinib therapy. The most recent computed tomography of the chest, abdomen, and pelvis shows an overall decrease in size of the right upper lobe mass and that other lesions are stable (Fig. 1C). The most recent brain magnetic resonance imaging (MRI) shows no evidence of enhancing brain lesion or acute intracranial abnormality (Fig. $1 F)$. The patient continues on therapy with clinically and radiologically stable disease with no treatment-related toxicities or other abnormalities.

\section{Genomic Analysis}

A next-generation sequencing panel of more than 50 genes identified MET c.3082G > A (NM_001127500.2) alteration located at the exon 14/intron 14 boundary of the MET proto-oncogene and a MET amplification equivocal. The testing also showed a number of variants of unknown significance including NFE2L2 c.1346G > A p. R449H (NM_006 164.4), NOTCH1 c.2705G > A p.R902H (NM_017617.4), PPP2R1A c.807 + 4del (NM_0142 25.5), and PIK3CA c.1610G > T p.R537L (NM_006218.3) (Table 1).

\section{DISCUSSION: THE ROLE OF TARGETED THERAPY IN METex14-MUTATED NSCLC}

The MET receptor tyrosine kinase and the ligand hepatocyte growth factor (HGF) have been implicated as oncogenes and drivers of NSCLC (Cipriani et al. 2009). Various aberrations in MET have different oncogenic potential, and the MET exon 14 skipping mutation in particular has been shown to be a strong oncogenic driver and can often function mutually exclusively from other oncogenes. This patient's tumor harbored a somatic mutation in exon 14 that has been characterized to result in exon 14 skipping, which leads to stabilization and constitutive activation of the mutated MET protein. Of note, this patient's point mutation was c.3082G > A (Salgia et al. 2020). MET alterations are substantially prevalent in lung cancer with an incident rate of $6 \%$ in lung adenocarcinoma and $3 \%$ in lung squamous cell carcinoma (The Cancer Genome Atlas Research Network 2012; Collisson et al. 2014). Our group was first to identify MET exon 14 skipping mutations in SCLC and NSCLC (Ma et al. $2003,2005)$, which were later found to be clinically actionable in 2015 , with inhibitors crizotinib and cabozantinib (Paik et al. 2015; Drilon et al. 2020), and are estimated to have an incidence rate of 3\%-4\% (Fujino et al. 2019). More recently, based on the results of the Phase II GEOMETRY mono-1 study, capmatinib, a selective type 1b MET inhibitor (Recondo et al. 2020; Salgia et al. 2020), with a median PFS of 9.13 months and overall response rate of $67.9 \%$, was granted U.S. Federal Drug Administration (FDA) approval as a novel MET inhibitor in the metastatic NSCLC setting and became the first approved MET tyrosine-kinase inhibitor (Wolf et al. 2019). Capmatinib also had activity in a cohort of 69 previously treated patients with objective response in $40 \%$ of cases and $75 \%$ of patients had stable disease (Wolf et al. 2017, 2018). More recent data also shows that capmatinib may have intracranial activity and that out of 13 patients with brain metastases, 7 (54\%) had intracranial response (Heist et al. 2019).

Similarly, tepotinib, a novel selective type $1 \mathrm{~b}$ MET inhibitor that inhibits MET phosphorylation and downstream signaling, has also been shown to be effective in patients with MET exon 14 mutations with a long duration of response (Paik et al. 2019). Although the initial results are promising, there is a shortage of information concerning the response to tepotinib therapy in patients with diffusely metastatic disease. Therefore, we described a patient with MET exon 14 mutation who sustained a complete resolution of multiple brain lesions and stable metastatic lesions while on tepotinib therapy. Tepotinib initially showed potent 


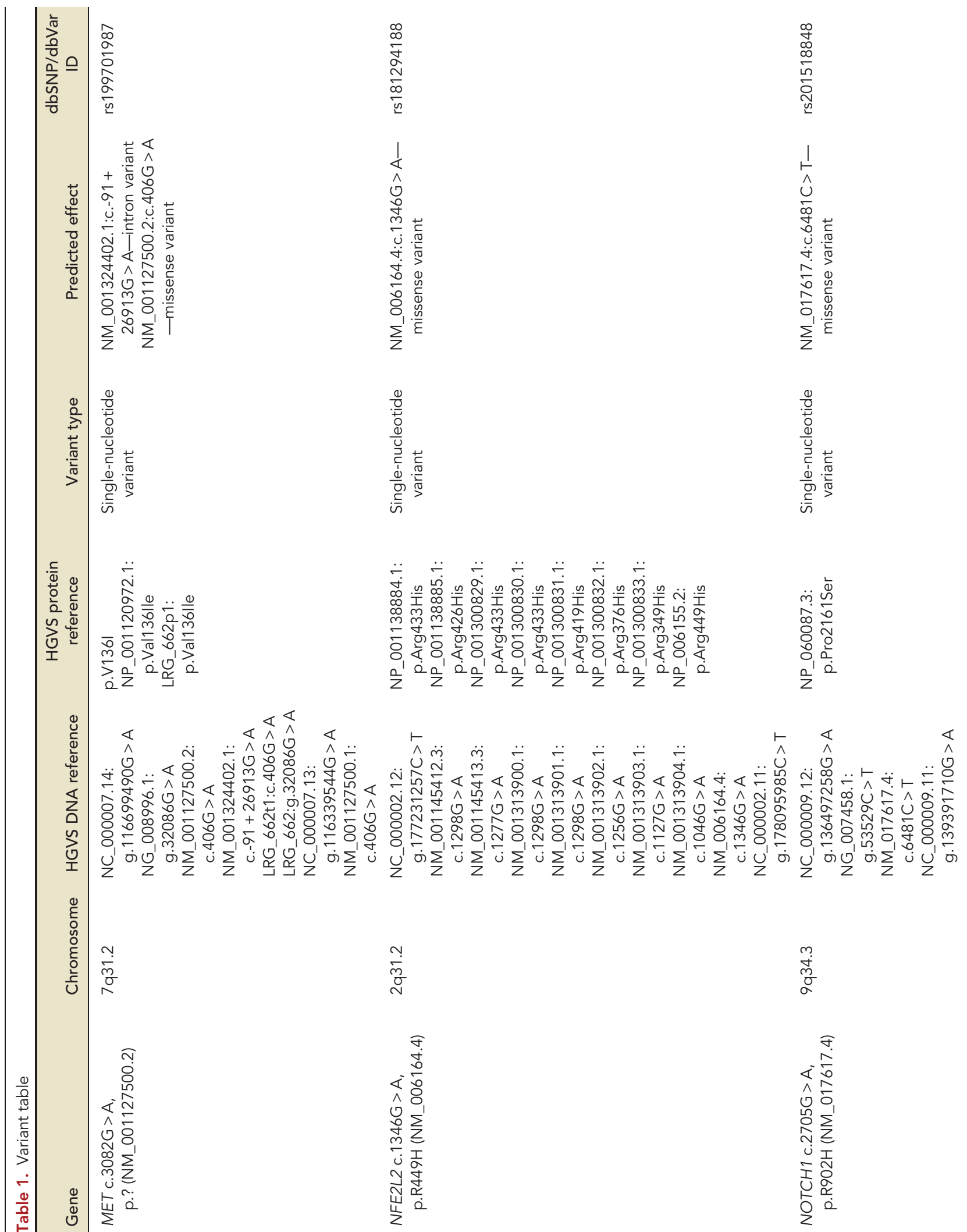




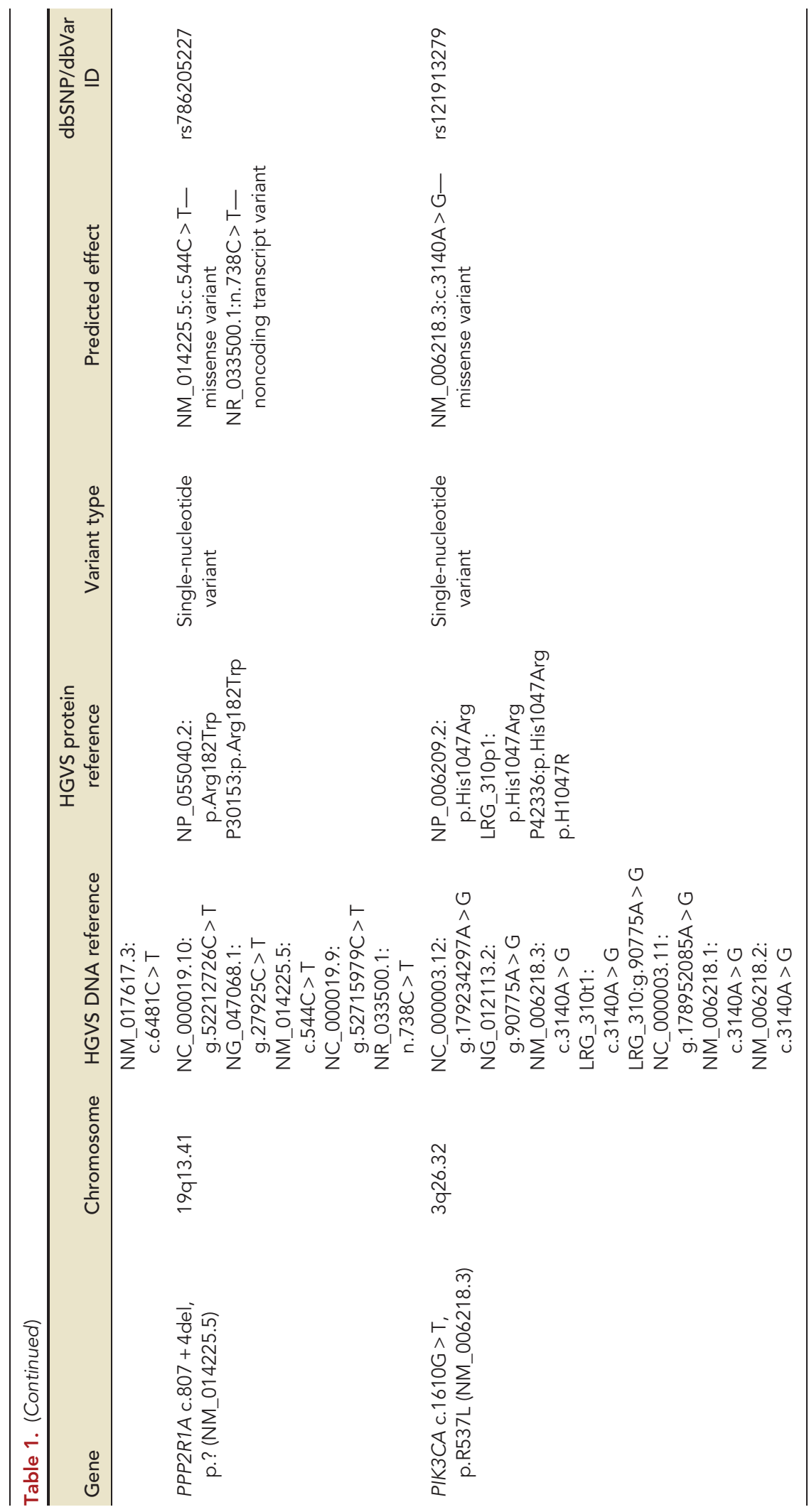


inhibitory activity against MET in cancer cell lines and antitumor activity in mouse xenograft models prior to in-human clinical trials. It also uniquely inhibits MET regardless of HGF-dependent or -independent MET activation (Bladt et al. 2013). In recent data from the phase II VISION study, $97 \%$ of patients had metastatic disease at study entry. The objective response rate was $46 \%$ with a median duration of response of $11.1 \mathrm{mo}$ and median progression-free survival of $8.5 \mathrm{mo}$. All responses were partial in independent review, although two patients were deemed to have a complete response by investigators. These results were superior to capmatinib in the pretreated group, with a response rate of $56 \%$ (vs. $41 \%$ ) suggesting the utility of tepotinib in the pretreated refractory setting (Heist et al. 2019).

Eleven percent of patients had brain metastases at study entry, although these were nontarget lesions, and the median duration of response for these patients was 9.5 mo and median progression-free survival was 10.9 mo (Paik et al. 2020). The incidence of brain metastases at diagnosis in patients with NSCLC harboring a MET exon 14 mutation is unknown, though intracranial resistance to first-generation MET TKIs such as crizotinib has been reported (Klempner et al. 2017). In the phase II VISION study, patients with brain metastases had a response rate of 55\% (Paik et al. 2020). The patient described in this case has had no recurrence of his brain metastases, which had resolved while on pembrolizumab, and stable disease for his other sites of disease for 31 mo on tepotinib therapy. Taken together, this suggests that tepotinib has activity in the front-line and the refractory setting, including in the brain.

It is noteworthy that this patient's tumor had high PD-L1 expression in addition to the MET exon 14 mutation. This patient had complete resolution of his brain metastases while on pembrolizumab therapy, and although he ultimately had progression of his primary lung mass and involved lymph nodes, he has had a sustained complete response of his brain metastases while on tepotinib therapy. It has been reported that $40 \%$ of patients with NSCLC with a MET exon 14 skipping mutation express high PD-L1, but they have an overall response rate of about one-third to pembrolizumab monotherapy (Sabari et al. 2017, 2018). In a study of 951 NSCLC East Asian patients, 16 were found to harbor a MET exon 14 skipping mutation, and PD-L1 was found to be highly expressed in the patients harboring MET exon 14 skipping (69.2\% vs. 17.3\%, $P<0.01$ ) (Xu et al. 2020). Examination of clinical and molecular characteristics of 298 patients with NSCLC harboring a MET exon 14 mutation but not concurrent MET amplification showed that $88.3 \%$ of patients had low or intermediate low mutation burden (TMB), and this characterization has been suggested as a possible explanation for the low response rate to pembrolizumab (Schrock et al. 2016). However, TMB has been a disappointing biomarker thus far, and as such its significance remains unclear. In this patient, it is clear that the MET exon 14 mutation is a driver mutation, but as this patient has had a durable response of his brain metastases without recurrence while on tepotinib, either he has a durable response of these lesions because of pembrolizumab or perhaps pembrolizumab has some sensitizing role that enhances the activity of subsequent TKI therapy, which is an area needing further exploration.

Genomic analysis also identified this patient's tumor to be equivocal for MET amplification, which at this time is not clinically actionable. De novo MET amplification has been identified as a carcinogenic driver and reported in $2.2 \%$ of patients with NSCLC (Collisson et al. 2014). It has been noted that tumors with de novo MET amplification have greater sensitivity to TKIs compared to tumors without it, and although the patient's MET amplification is equivocal, perhaps it contributes to this patient's prolonged response to tepotinib (Camidge et al. 2014; Suryavanshi et al. 2017).

Finally, genomic analysis of this patient's tumor also identified a variant of uncertain significance (VUS) in exon 10 of the PIK3CA gene resulting in an arginine to leucine substitution at amino acid 537 in the patient's tumor. However, this was present in $<10 \%$ of the sequencing reads, which is less than the stated limit of detection of the assay per the report. 
Competing Interest Statement

The authors have declared no competing interest.

\section{Referees}

Robert Aiken

Anonymous

Received July 26, 2020; accepted in revised form September 24, 2020.
Mutations in PIK3CA occur in $~ 7 \%$ of NSCLCs, and the most common mutated hotspots for this gene are in exon 9 (Collisson et al. 2014). This alteration has been demonstrated in vitro as a possible mechanism of primary resistance to MET-TKIs in patients harboring a MET exon 14 skipping mutation, and continued attention to alterations in this gene, particularly in patients whose tumors also harbor a pathogenic mutation in MET, is certainly warranted (Jamme et al. 2020).

\section{METHODS}

The patient's tumor tissue was analyzed with OncoPlus (v2.0), somatic testing using nextgeneration sequencing. The panel is a commercial targeted panel service available as an insurance-reimbursable CLIA assay (Supplemental Tables S1 and S2).

\section{ADDITIONAL INFORMATION}

\section{Data Deposition and Access}

The pathogenic variant was submitted to ClinVar (https://www.ncbi.nlm.nih.gov/clinvar/) and can be found under accession number VCV000983225.1.

\section{Ethics Statement}

The City of Hope Institutional Review Board approved this study and informed consent was obtained under IRB\# 07047.

\section{Acknowledgments}

The authors would like to thank City of Hope nurses and supportive staff for their dedication to their patients.

\section{Author Contributions}

K.G.R. and I.M. contributed equally to this work and should be considered co-first authors. K.G.R., I.M., and R.S. participated in the conceptualization, methodology, data curation, original draft preparation, and reviewing and editing the final manuscript. R.S. provided supervision and funding.

\section{Funding}

The work was supported by the National Cancer Institute of the National Institutes of Health under award numbers P30CA033572, U54CA209978, R01CA247471, and R01CA218545.

\section{REFERENCES}

Bladt F, Faden B, Friese-Hamim M, Knuehl C, Wilm C, Fittschen C, Grädler U, Meyring M, Dorsch D, Jaehrling F, et al. 2013. EMD 1214063 and EMD 1204831 constitute a new class of potent and highly selective c-Met inhibitors. Clin Cancer Res 19: 2941-2951. doi:10.1158/1078-0432.CCR-12-3247

Camidge DR, Ou S-HI, Shapiro G, Otterson GA, Villaruz LC, Villalona-Calero MA, lafrate AJ, Varella-Garcia M, Dacic S, Cardarella S, et al. 2014. Efficacy and safety of crizotinib in patients with advanced c-MET-amplified non-small cell lung cancer (NSCLC). J Clin Oncol 32: 8001.

Cipriani NA, Abidoye OO, Vokes E, Salgia R. 2009. MET as a target for treatment of chest tumors. Lung Cancer 63: 169-179. doi:10.1016/j.lungcan.2008.06.011 
Collisson EA, Campbell JD, Brooks AN, Berger AH, Lee W, Chmielecki J, Beer DG, Cope L, Creighton CJ, Danilova $L$, et al. 2014. Comprehensive molecular profiling of lung adenocarcinoma. Nature 511: 543550. doi:10.1038/nature13385

Drilon A, Clark JW, Weiss J, Ou S-HI, Camidge DR, Solomon BJ, Otterson GA, Villaruz LC, Riely GJ, Heist RS, et al. 2020. Antitumor activity of crizotinib in lung cancers harboring a MET exon 14 alteration. Nat Med 26: 47-51. doi:10.1038/s41591-019-0716-8

Fujino T, Kobayashi Y, Suda K, Koga T, Nishino M, Ohara S, Chiba M, Shimoji M, Tomizawa K, Takemoto T, et al. 2019. Sensitivity and resistance of MET exon 14 mutations in lung cancer to eight MET tyrosine kinase inhibitors in vitro. J Thorac Oncol 14: 1753-1765. doi:10.1016/j.jtho.2019.06.023

Heist RS, Wolf J, Seto T, Han JY, Reguart N, Groen HJM, Tan DSW, Hida T, Jonge MD, Orlov SV, et al. 2019. OA01.07 Capmatinib (INC280) in MET $\Delta$ ex14-mutated advanced NSCLC: efficacy data from the phase 2 geometry MONO-1 study. J Thorac Oncol 14: S1126.

Jamme P, Fernandes M, Copin M-C, Descarpentries C, Escande F, Morabito A, Grégoire V, Jamme M, Baldacci S, Tulasne D, et al. 2020. Alterations in the PI3K pathway drive resistance to MET inhibitors in NSCLC harboring MET exon 14 skipping mutations. J Thorac Oncol 15: 741-751. doi:10.1016/j.jtho 2020.01.027

Kim K-H, Kim H. 2017. Progress of antibody-based inhibitors of the HGF-cMET axis in cancer therapy. Exp Mol Med 49: e307. doi:10.1038/emm.2017.17

Klempner SJ, Borghei A, Hakimian B, Ali SM, Ou SI. 2017. Intracranial activity of cabozantinib in MET exon 14positive NSCLC with brain metastases. J Thorac Oncol. 12: 152-156. doi:10.1016/j.jtho.2016.09.127

Ma PC, Kijima T, Maulik G, Fox EA, Sattler M, Griffin JD, Johnson BE, Salgia R. 2003. c-MET mutational analysis in small cell lung cancer: novel juxtamembrane domain mutations regulating cytoskeletal functions. Cancer Res 63: 6272-6281.

Ma PC, Jagadeeswaran R, Jagadeesh S, Tretiakova MS, Nallasura V, Fox EA, Hansen M, Schaefer E, Naoki K, Lader A, et al. 2005. Functional expression and mutations of c-Met and its therapeutic inhibition with SU11274 and small interfering RNA in non-small cell lung cancer. Cancer Res 65: 1479-1488. doi:10 .1158/0008-5472.CAN-04-2650

Ma Y, Zhang M, Wang J, Huang X, Kuai X, Zhu X, Chen Y, Jia L, Feng Z, Tang Q, et al. 2019. High-affinity human anti-c-Met lgG conjugated to oxaliplatin as targeted chemotherapy for hepatocellular carcinoma. Front Oncol 9: 717. doi:10.3389/fonc.2019.00717

Paik PK, Drilon A, Fan PD, Yu H, Rekhtman N, Ginsberg MS, Borsu L, Schultz N, Berger MF, Rudin CM, et al. 2015. Response to MET inhibitors in patients with stage IV lung adenocarcinomas harboring MET mutations causing exon 14 skipping. Cancer Discov 5: 842-849. doi:10.1158/2159-8290.CD-14-1467

Paik PK, Veillon R, Cortot AB, Felip E, Sakai H, Mazieres J, Griesinger F, Horn L, Senellart H, Meerbeeck JPV, et al. 2019. Phase II study of tepotinib in NSCLC patients with METex14 mutations. J Clin Oncol 37: 9005.

Paik PK, Felip E, Veillon R, Sakai H, Cortot AB, Garassino MC, Mazieres J, Viteri S, Senellart H, Van Meerbeeck $\mathrm{J}$, et al. 2020. Tepotinib in non-small-cell lung cancer with MET exon 14 skipping mutations. N Engl J Med 383: 931-943. doi:10.1056/NEJMoa2004407

Recondo G, Bahcall M, Spurr LF, Che J, Ricciuti B, Leonardi GC, Lo YC, Li YY, Lamberti G, Nguyen T, et al. 2020. Molecular mechanisms of acquired resistance to MET tyrosine kinase inhibitors in patients with MET exon 14-mutant NSCLC. Clin Cancer Res 26: 2615-2625. doi:10.1158/1078-0432.CCR-19-3608

Sabari JK, Montecalvo J, Chen R, Dienstag JA, Mrad C, Bergagnini I, Lai W-CV, Arbour KC, Shu CA, Hellmann MD, et al. 2017. PD-L1 expression and response to immunotherapy in patients with MET exon 14-altered non-small cell lung cancers (NSCLC). J Clin Oncol 35: 8512.

Sabari JK, Leonardi GC, Shu CA, Umeton R, Montecalvo J, Ni A, Chen R, Dienstag J, Mrad C, Bergagnini I, et al. 2018. PD-L1 expression, tumor mutational burden, and response to immunotherapy in patients with MET exon 14 altered lung cancers. Ann Oncol 29: 2085-2091. doi:10.1093/annonc/mdy334

Salgia R, Sattler M, Scheele J, Stroh C, Felip E. 2020. The promise of selective MET inhibitors in non-small cell lung cancer with MET exon 14 skipping. Cancer Treat Rev 87: 102022. doi:10.1016/j.ctrv.2020.102022

Schrock AB, Frampton GM, Suh J, Chalmers ZR, Rosenzweig M, Erlich RL, Halmos B, Goldman J, Forde P, Leuenberger K, et al. 2016. Characterization of 298 patients with lung cancer harboring MET exon 14 skipping alterations. J Thorac Oncol 11: 1493-1502. doi:10.1016/j.jtho.2016.06.004

Suryavanshi M, Shah A, Kumar D, Panigrahi MK, Metha A, Batra U. 2017. MET amplification and response to MET inhibitors in stage IV lung adenocarcinoma. Oncol Res Treat 40: 198-202. doi:10.1159/000457801

The Cancer Genome Atlas Research Network. 2012. Comprehensive genomic characterization of squamous cell lung cancers. Nature 489: 519-525. doi:10.1038/nature11404

Wolf J, Han J, Nishio M, Souquet P, Paz-Ares L, De Marinis F, Seto T, De Jonge M, Kim TM, Vansteenkiste J, et al. 2017. PS04.06 GEOMETRY mono-1: phase II, multicenter study of MET inhibitor capmatinib (INC280) in EGFR wt, MET-dysregulated advanced NSCLC: topic: medical oncology. J Thorac Oncol 12: S1578S1579. doi: 10.1016/j.jtho.2017.09.075 
Wolf J, Seto T, Han JY, Reguart N, Garon EB, Groen HJM, Tan DS, Hida T, de Jonge MJA, Orlov SV, et al. 2018. Results of the GEOMETRY mono-1 phase II study for evaluation of the MET inhibitor capmatinib (INC280) in patients (pts) with METAex14 mutated advanced non-small cell lung cancer (NSCLC). Ann Oncol 29: viii741-viii742. doi:10.1093/annonc/mdy424.090

Wolf J, Seto T, Han J-Y, Reguart N, Garon EB, Groen HJM, Tan DS-W, Hida T, Jonge MJD, Orlov SV, et al. 2019. Capmatinib (INC280) in METAex14-mutated advanced non-small cell lung cancer (NSCLC): efficacy data from the phase II GEOMETRY mono-1 study. J Clin Oncol 37: 9004.

Xu Z, Li H, Dong Y, Cheng P, Luo F, Fu S, Gao M, Kong L, Che N. 2020. Incidence and PD-L1 expression of MET 14 skipping in Chinese population: a non-selective NSCLC cohort study using RNA-based sequencing. Onco Targets Ther 13: 6245-6253. doi:10.2147/OTT.S241231 


\section{COLD SPRING HARBOR Molecular Case Studies}

\section{Prolonged survival and response to tepotinib in a non-small-cell lung cancer patient with brain metastases harboring MET exon 14 mutation: a research report}

Katherine G. Roth, Isa Mambetsariev and Ravi Salgia

Cold Spring Harb Mol Case Stud 2020, 6: a005785

Access the most recent version at doi: $10.1101 / \mathrm{mcs} . a 005785$

Supplementary
Material $\quad \underset{C 1}{\text { http://molecularcasestudies.cshlp.org/content/suppl/2020/12/17/mcs.a005785.D }}$

References This article cites 27 articles, 5 of which can be accessed free at: http://molecularcasestudies.cshlp.org/content/6/6/a005785.full.html\#ref-list-1

License This article is distributed under the terms of the Creative Commons Attribution-NonCommercial License, which permits reuse and redistribution, except for commercial purposes, provided that the original author and source are credited.

Email Alerting Receive free email alerts when new articles cite this article - sign up in the box at the Service top right corner of the article or click here. 